BMJ Open

Diabetes

Research

\& Care

\section{Sex differences in glycemic measures, complications, discharge disposition, and postdischarge emergency room visits and readmission among non- critically ill, hospitalized patients with diabetes}

To cite: Patel N, Swami J, Pinkhasova D, et al. Sex differences in glycemic measures, complications, discharge disposition, and postdischarge emergency room visits and readmission among non-critically ill, hospitalized patients with diabetes. BMJ Open Diab Res Care 2022;10:e002722. doi:10.1136/

bmjdrc-2021-002722

Results from this study have been presented in abstract form at the American Diabetes Association and the Endocrine Society.

Received 9 December 2021 Accepted 9 February 2022

Check for updates

C Author(s) (or their employer(s)) 2022. Re-use permitted under CC BY-NC. No commercial re-use. See rights and permissions. Published by BMJ.

For numbered affiliations see end of article.

Correspondence to Dr Mary T Korytkowski; mtk7@pitt.edu

\section{ABSTRACT}

Introduction The purpose of this prospective observational cohort study was to examine sex differences in glycemic measures, diabetes-related complications, and rates of postdischarge emergency room (ER) visits and hospital readmissions in non-critically ill, hospitalized patients with diabetes.

Research design and methods Demographic data including age, body mass index, race, blood pressure, reason for admission, diabetes medications at admission and discharge, diabetes-related complications, laboratory data (hematocrit, creatinine, hemoglobin A1c, pointof-care blood glucose measures), length of stay (LOS), and discharge disposition were collected. Patients were followed for 90 days following hospital discharge to obtain information regarding ER visits and readmissions.

Results 120 men and 100 women consented to participate in this study. There were no sex differences in patient demographics, diabetes duration or complications, or LOS. No differences were observed in the percentage of men and women with an ER visit or hospital readmission within $30(39 \%$ vs $33 \%, p=0.40)$ or $90(60 \%$ vs $49 \%$, $\mathrm{p}=0.12$ ) days of hospital discharge. More men than women experienced hypoglycemia prior to discharge ( $18 \%$ vs $8 \%$, $p=0.026)$. More women were discharged to skilled nursing facilities $(p=0.007)$.

Conclusions This study demonstrates that men and women hospitalized with an underlying diagnosis of diabetes have similar preadmission glycemic measures, diabetes duration, and prevalence of diabetes complications. More men experienced hypoglycemia prior to discharge. Women were less likely to be discharged to home. Approximately $50 \%$ of men and women had ER visits or readmissions within 90 days of hospital discharge. Trial registration number NCT03279627.

\section{INTRODUCTION}

According to the Center for Disease Control, 17.9 million men and 16.2 million women in

\section{Significance of this study}

What is already known about this subject?

- Hospitalized men and women with diabetes have higher rates of hospital admissions and readmissions than sexmatched populations without diabetes.

- Much of the literature reporting sex differences in hospitalizations and readmissions is related to patient populations hospitalized with cardiovascular disorders.

What are the new findings?

$\checkmark$ Men with diabetes experienced more hypoglycemia prior to discharge, and women with diabetes were more likely to be discharged to a skilled nursing facility.

- Men and women experienced a similar frequency of emergency room (ER) visits and hospital readmissions within 30 and 90 days following hospital discharge.

How might these results change the focus of research or clinical practice?

- The high rates of ER visits and hospital readmissions in men and women with diabetes support the need for interventions that can ameliorate this risk in the future.

- The factors that contribute to this higher readmission risk may be different for men and women and are worthy of future investigation.

the USA had a diagnosis of diabetes in $2018 .{ }^{1}$ Higher per capita healthcare expenditures are reported in men with diabetes, but higher lifetime healthcare expenditures are reported in women. ${ }^{2-4}$ These higher costs in women may be due in part to social factors such as lower levels of education, employment, and socioeconomic status, which hinder access to healthcare and healthy lifestyles. ${ }^{56}$ These factors in turn have the potential to increase the risk of diabetesrelated complications and associated comorbidities such as cardiovascular disease (CVD), which 
may lead to hospitalization, a major contributor to healthcare costs in people with diabetes. ${ }^{5}$

Both men and women with diabetes have a higher lifetime likelihood of being hospitalized. ${ }^{78}$ Diabetes is identified as an underlying comorbidity in approximately $25 \%$ of all adult hospitalized patients and is also identified as a predictor of risk of hospital readmission. ${ }^{910}$ There is little information available regarding sex differences among hospitalized patients with diabetes or as a contributor to risk of readmission. ${ }^{11-15}$

There is increasing attention to reducing overall healthcare costs in the USA by reducing the frequency of preventable hospital readmissions. ${ }^{16}{ }^{17}$ Women with diabetes have higher population-adjusted rates for both hospitalization and readmission when compared with men or women without diabetes. ${ }^{18}{ }^{19}$ In one study examining national trends in hospital admissions, there was a greater increase in hospitalizations among women compared with men with diabetes, which was more pronounced in women aged 20-39 years. ${ }^{18}$

The Nationwide Readmissions Database demonstrated that diabetes increased the risk of readmission following percutaneous coronary intervention (PCI) to a greater extent in women compared with men. ${ }^{20}$ Flink $e t a l^{21}$ reported an 8.5-fold increased risk of 30-day hospital readmissions for cardiovascular events among women but not men with poor glycemic measures when stratifying for demographics, medical history, discharge diagnosis, medical therapy, and reason for hospitalization. One retrospective analysis of hospitalizations identified female sex but not diabetes as an independent predictor of 30-day readmission for heart failure and recurrent coronary events following hospitalization for acute coronary syndrome requiring PCI. ${ }^{22}$

The Readmission and Comprehension of Diabetes Education at Discharge study is a prospective, non-blinded, observational study that examined the factors associated with risk of hospital readmission among patients with diabetes as a secondary diagnosis. ${ }^{23}$ This analysis was conducted to examine sex differences in demographics, metabolic and glycemic measures, diabetes-related complications, discharge disposition, and frequency of emergency room (ER) visits and readmissions within 90 days following an index hospitalization.

\section{METHODS}

This was a prospective, non-blinded, observational cohort study conducted at a single academic medical center.

\section{Patient recruitment}

Non-pregnant, non-critically ill, hospitalized patients with a secondary diagnosis of diabetes aged 18-90 years were recruited for this study between July 2017 and December 2018. Patients admitted with a primary diagnosis of hypoglycemia, diabetic ketoacidosis, or hyperglycemic hyperosmolar syndrome were excluded as were patients treated with insulin pump therapy. Potential subjects were identified from the general medicine service, the inpatient endocrine and diabetes consult services, and from daily reports of patients experiencing blood glucose (BG) $<70 \mathrm{mg} / \mathrm{dL}$ and $>300 \mathrm{mg} / \mathrm{dL}$. A member of the study team approached the patients meeting the inclusion criteria to discuss the study and obtain consent. All participants provided written informed consent prior to data collection or study procedures.

\section{Data collection}

The following demographic data were collected through patient interviews and chart review: age, sex, body mass index (BMI), blood pressure (BP), duration and type of diabetes, employment status, educational level, date of most recent prior hospitalization, hemoglobin Alc (HbA1c), reason for admission, history of microvascular (retinopathy, neuropathy, nephropathy) or macrovascular (coronary artery disease, cerebrovascular event, peripheral vascular disease) diabetic-related complications, laboratory data (estimated glomerular filtration rate (eGFR), serum sodium, albumin, hematocrit), length of stay (LOS), discharge disposition, and admission and discharge diabetes medications.

Up to 10 BG measures obtained during the 48-hour time period preceding hospital discharge were obtained. Glucose values were measured in 4-hour intervals using either the lowest or the highest values if there were multiple measures in any one 4-hour interval to avoid overcounting of high or low BG values. For the majority of participants, BG measures were obtained before meals and bedtime in patients who were eating or every 6 hours in patients who were not eating.

Associations between nadir, peak, and mean BG values as well as glycemic variability measured as $\mathrm{SD}$, coefficient of variability $(\mathrm{CV})$, and $\mathrm{BG}$ range were investigated. A Diabetes Early Readmission Risk Indicator (DERRI) score was calculated for each patient and correlated with ER visits and hospital readmissions within 30 and 90 days following the index hospitalization. ${ }^{1024}$

Study participants were contacted at 30 and 90 days following discharge to obtain information about ER visits and hospital readmissions. Information provided by the patients was validated by review of data available in the electronic health record (EHR). Information regarding ER visits and readmissions was obtained from the EHR for patients who could not be reached for a phone interview.

\section{Statistical analysis}

Descriptive statistics were reported using mean and SD or median with IQR for continuous variables, and frequencies with percentages for categorical variables. A t-test or a Mann-Whitney U test was performed to compare continuous variables and $\chi^{2}$ or Fisher's exact test was used to compare categorical variables between men and women. Data were analyzed using SPSS V.24.0. Statistical significance was defined as $\mathrm{p}<0.05$.

\section{RESULTS}

\section{Study population}

Of the 240 patients who consented to participate in this study, 20 were excluded. Reasons for exclusion included deterioration of clinical status during the 


\section{Assessed for eligibility $(n=4382)$}

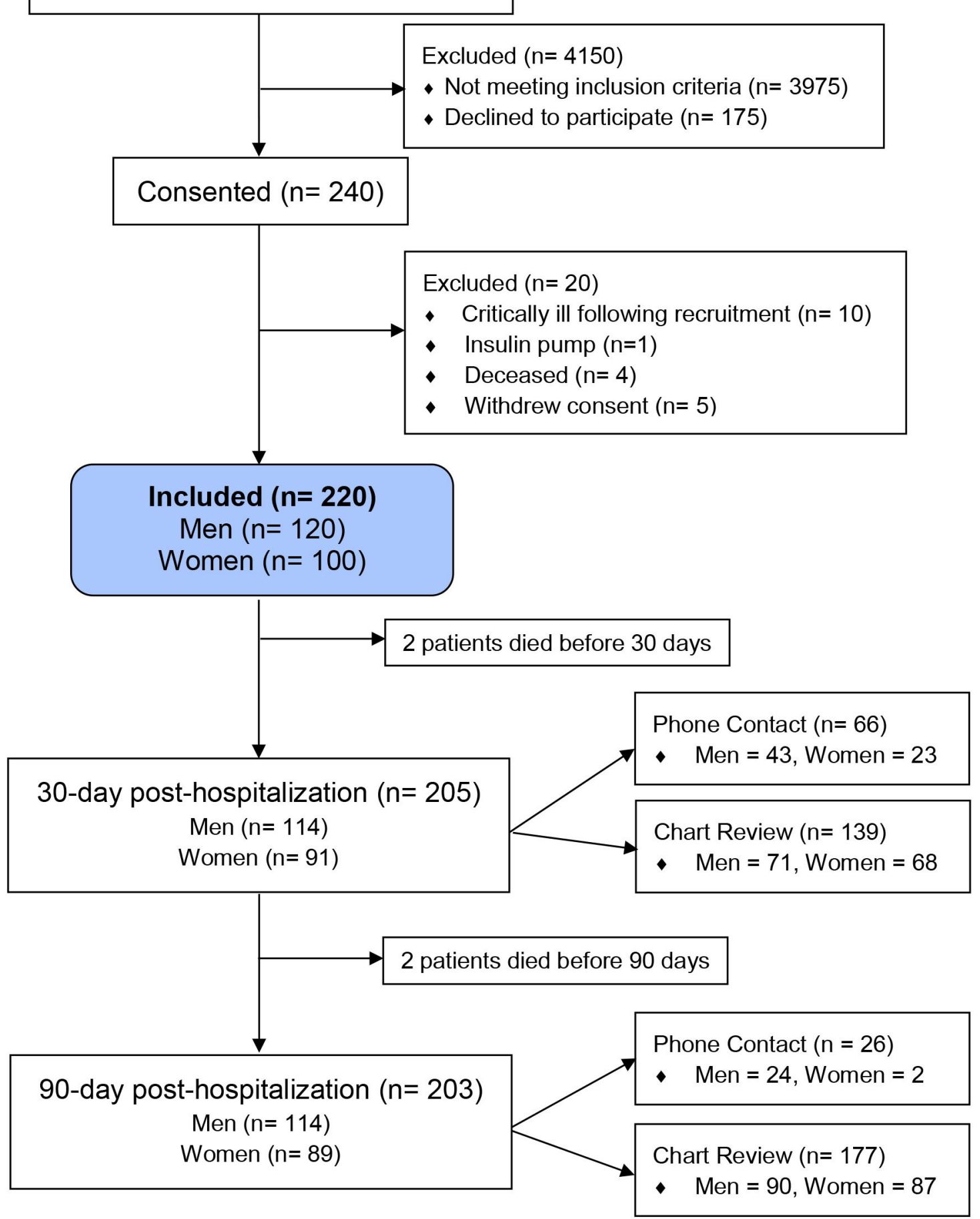

Figure 1 CONSORT diagram showing participant recruitment and disposition. CONSORT, Consolidated Standards of Reporting Trials.

index hospitalization $(\mathrm{n}=10)$, use of an insulin pump $(n=1)$, withdrawal of consent $(n=5)$, or death prior to discharge $(n=4)$ (figure 1$)$. The 220 remaining participants included 120 men and 100 women, the majority of whom had type 2 diabetes (table 1 ).

Table 1 shows the clinical characteristics of study participants. There were no significant differences observed for age, race, BMI, BP, HbA1c, duration of diabetes, educational or employment status, glycemic measures preceding hospital discharge, hematocrit, LOS, DERRI scores, or hospital LOS between men and women. Serum creatinine was lower in women but there was no difference in eGFR. The percentage of men and women with microvascular, neuropathic, and macrovascular complications was also similar. The women in this study were less likely to be discharged to home with or without home 
Table 1 Clinical characteristics of study participants by sex*

\begin{tabular}{|c|c|c|c|}
\hline & Men $(n=120)$ & Women $(n=100)$ & $P$ value \\
\hline Age (years) & $61.1 \pm 11.8$ & $58.3 \pm 11.7$ & 0.77 \\
\hline Race, white, n (\%) & $92(76.7)$ & $74(74.0)$ & 0.647 \\
\hline $\operatorname{BMI}\left(\mathrm{kg} / \mathrm{m}^{2}\right)$ & $32 \pm 8$ & $32.3 \pm 10$ & 0.791 \\
\hline Systolic BP (mm Hg) & $132.8 \pm 25.3$ & $127 \pm 22.3$ & 0.076 \\
\hline Diastolic BP (mm Hg) & $74.9 \pm 12.6$ & $73.9 \pm 13.7$ & 0.572 \\
\hline Education, above high school, n (\%) & $52(43.3)$ & $47(47)$ & 0.586 \\
\hline Employment, n (\%) & & & 0.134 \\
\hline Unemployed & $41(34.2)$ & $25(25)$ & \\
\hline Employed & $22(18.3)$ & $23(23)$ & \\
\hline Retired & $35(29.2)$ & $23(23)$ & \\
\hline Disabled & $22(18.3)$ & $29(29)$ & \\
\hline Diabetes type $1 / 2 /$ other, $n(\%)$ & $9(7) / 104(87) / 7(6)$ & $8(8) / 80(80) / 12(12)$ & 0.353 \\
\hline HbA1c (\%) & $8.2 \pm 2$ & $8.4 \pm 2.28$ & 0.473 \\
\hline Diabetes duration (years) & $15.9 \pm 10.4$ & $14.1 \pm 11.3$ & 0.237 \\
\hline Number of diabetes complications & $2.4 \pm 1.5$ & $2.3 \pm 1.9$ & 0.736 \\
\hline Length of stay (days), median (IQR) & $6.0(3.5-9.2)$ & $6.8(4.1-11.2)$ & 0.152 \\
\hline \multicolumn{4}{|l|}{ Complications, $\mathrm{n}(\%)$} \\
\hline Retinopathy & $41(25)$ & $19(19)$ & 0.287 \\
\hline Nephropathy & $45(38)$ & $28(28)$ & 0.106 \\
\hline Neuropathy & $71(59)$ & $63(63)$ & 0.562 \\
\hline CAD & $61(51)$ & $39(39)$ & 0.079 \\
\hline $\mathrm{CHF}$ & $43(36)$ & $37(37)$ & 0.858 \\
\hline CVA & $19(16)$ & $20(20)$ & 0.420 \\
\hline PVD & $23(19)$ & $21(21)$ & 0.735 \\
\hline Reason for admission, $\mathrm{n}(\%)$ & & & 0.442 \\
\hline Cardiac & $43(35)$ & $26(26)$ & \\
\hline Pulmonary & $4(3)$ & $5(5)$ & \\
\hline Infection & $17(14)$ & $21(21)$ & \\
\hline Trauma/injury & $4(3)$ & $5(5)$ & \\
\hline Transplant & $8(7)$ & $4(4)$ & \\
\hline Other & $44(37)$ & $39(39)$ & \\
\hline \multicolumn{4}{|l|}{ Laboratory measures, median (IQR) } \\
\hline Creatinine, mg/dL & $1.3(1.0-2.0)$ & $1.0(0.7-1.5)$ & $<0.001$ \\
\hline eGFR, $\mathrm{mL} / \mathrm{min} / \mathrm{m}^{2}$ & $58.5(34-60)$ & $60.0(40-60)$ & 0.186 \\
\hline Sodium, mmol/L & $136(134-139)$ & $138(135-139)$ & 0.142 \\
\hline Albumin, $\mathrm{g} / \mathrm{L}$ & $3.5(3.0-3.8)$ & $3.6(3.0-3.9)$ & 0.687 \\
\hline Hematocrit (\%) & $34.3(29.5-38.3)$ & $34.0(30.7-38.2)$ & 0.975 \\
\hline Disposition, n (\%) & & & 0.007 \\
\hline Home & $118(98)$ & $90(90)$ & \\
\hline Discharge to SNF & $2(1.6)$ & $10(10)$ & \\
\hline DERRI score & $24.2 \pm 12.6$ & $21.8 \pm 10.9$ & 0.221 \\
\hline
\end{tabular}

${ }^{*}$ Results are mean \pm SD unless otherwise indicated.

$\mathrm{BMI}$, body mass index; BP, blood pressure; CAD, Coronary artery disease; CHF, Congestive heart failure; CVA, Cerebrovascular accident; DERRI, Diabetes Early Readmission Risk Indicator; eGFR, estimated glomerular filtration rate; HbA1c, hemoglobin A1c; PVD, Peripheral vascular disease; SNF, skilled nursing facility. 


\begin{tabular}{|c|c|c|c|}
\hline & $\begin{array}{l}\text { Men } \\
\text { n (\%) }\end{array}$ & $\begin{array}{l}\text { Women } \\
\text { n (\%) }\end{array}$ & $P$ value \\
\hline \multicolumn{4}{|l|}{ Diabetes medications at admission } \\
\hline Insulin only & $64(53)$ & $54(54)$ & 0.658 \\
\hline Insulin+non-insulin agents & $28(23)$ & $19(19)$ & \\
\hline Non-insulin agents only & $25(21)$ & $26(26)$ & \\
\hline None & $4(3)$ & $1(1)$ & \\
\hline \multicolumn{4}{|l|}{ Diabetes medications at discharge } \\
\hline Insulin only & $79(66)$ & $57(57)$ & 0.444 \\
\hline Insulin+non-insulin agents & $23(19)$ & $22(22)$ & \\
\hline Non-insulin agents only & $17(14)$ & $18(18)$ & \\
\hline None & $1(1)$ & $3(3)$ & \\
\hline $\begin{array}{l}\text { Patients (\%) with change in } \\
\text { diabetes medications between } \\
\text { admission and discharge }\end{array}$ & $71(59)$ & $49(49)$ & 0.132 \\
\hline
\end{tabular}

services and more likely to be discharged to a skilled nursing facility following the index hospitalization $(1.6 \%$ vs $10 \%, \mathrm{p}=0.007)$.

The most common reasons for admission included cardiovascular diagnoses (heart failure, myocardial infarction, heart rhythm abnormalities) and infection. Of the three most common reasons for admission, heart failure was listed as the primary reason for admission in $18.3 \%$ of men and $11 \%$ of women and myocardial infarction in $14.2 \%$ of men and $12 \%$ of women. Infection was the primary reason for admission in $12.5 \%$ of men and $18 \%$ of women.

The percentages of participants using insulin alone, insulin in combination with non-insulin therapies, or only non-insulin medications were similar between men and women prior to admission, during the index hospitalization, and at discharge (table 2). The majority of patients received insulin therapy alone $(66 \%$ and $57 \%)$ or in combination with non-insulin therapy (19\% vs $22 \%$, $\mathrm{p}=0.444$ ) during the index hospitalization. Changes in diabetes medications between admission and discharge occurred in $59 \%$ of men and $49 \%$ of women $(\mathrm{p}=0.132)$. Adjustment of insulin regimen (either insulin dose or type) was the most common change on discharge, occurring in $35 \%$ of men and $28 \%$ of women.

Nadir, peak, mean BG, and measures of glycemic variability (CV, SD, and BG range) during the 48-hour time period preceding hospital discharge were similar among men and women (table 3). Hypoglycemic but not hyperglycemic events in the 48-hour time period preceding hospital discharge occurred more frequently in men than in women. Among those experiencing hypoglycemia, three men and one woman experienced two BG values $<70 \mathrm{mg} / \mathrm{dL}$. Six men and three women had clinically significant hypoglycemia with BG values $<54 \mathrm{mg}$ / dL. Subgroup analysis of patients who did or did not experience hypoglycemia found no sex differences in
Table 3 Glycemic outcome measures 48 hours preceding hospital discharge*

\begin{tabular}{llll}
\hline & Men & Women & P value \\
\hline Nadir BG, mg/dL & $117.8 \pm 47.6$ & $120.7 \pm 41.6$ & 0.525 \\
\hline Peak BG, mg/dL & $294.8 \pm 81.6$ & $299.3 \pm 110.7$ & 0.846 \\
Mean BG, mg/dL & $196.5 \pm 51.4$ & $197.1 \pm 52.6$ & 0.977 \\
SD, mg/dL & $57.8 \pm 25.9$ & $59.1 \pm 34.5$ & 0.914 \\
BG range, mg/dL & $177.0 \pm 77.5$ & $178.6 \pm 108.7$ & 0.676 \\
$\begin{array}{l}\text { Percentage of } \\
\text { participants with } \\
\text { BG } \geq 1 \mathrm{mg} / \mathrm{dL} \text { and } \\
<70 \mathrm{mg} / \mathrm{dL}\end{array}$ & $22(18)$ & $8(8)$ & 0.026 \\
\hline
\end{tabular}

${ }^{*}$ Data presented as mean \pm SD.

$\mathrm{BG}$, blood glucose.

readmissions or ER visits at $30(\mathrm{p}=1.0)$ or $90(\mathrm{p}=0.403)$ days.

Prior to the index hospitalization, $52 \%$ and $64 \%$ of men and $46 \%$ and $56 \%$ of women reported being hospitalized within the prior 90 days and 1 year, respectively $(\mathrm{p}=\mathrm{NS})$. Following the index hospitalization, men and women experienced a similar number of ER visits and hospital readmissions within the next 30 and 90 days of discharge (figure 2). The majority of participants in this study were white. Subgroup analysis by race and sex for readmissions or ER visits found no differences at 30 $(\mathrm{p}=0.384)$ or $90(\mathrm{p}=0.516)$ days. The absolute number of hospital readmissions per patient at 30 days $(0.41 \pm 0.57$ vs $0.34 \pm 0.57, \mathrm{p}=0.144)$ and 90 days $(0.82 \pm 1.04$ vs $0.76 \pm 1.20$, $\mathrm{p}=0.258$ ) was also similar.

\section{DISCUSSION}

This study demonstrates that men and women hospitalized with a secondary diagnosis of diabetes have similar diabetes duration, prevalence of diabetes-related complications, and glycemic measures as measured by HbAlc. There were no sex differences in the percentage of participants receiving insulin therapy alone or in combination with non-insulin therapies before, during, or following the index hospitalization. More women were discharged to a skilled nursing facility following the index hospitalization compared with men. This suggests the possibility of higher level of disability and/or less home support. Although there were no significant differences in employment status between men and women, a higher percentage of women were identified as disabled (table 1). The presence of adequate social support has been identified as an important component for facilitating the discharge process and preventing hospital readmission in patients with diabetes and other disorders. $^{25} 26$

Cardiovascular disorders including heart failure, myocardial infarction, heart rhythm abnormalities, and infection were the most common reasons for admission among both men and women. Individuals with diabetes are at increased risk of CVD; however, this increase in 


\section{Sex Differences in 30 and 90 day ER Visits and Hospital Readmissions}

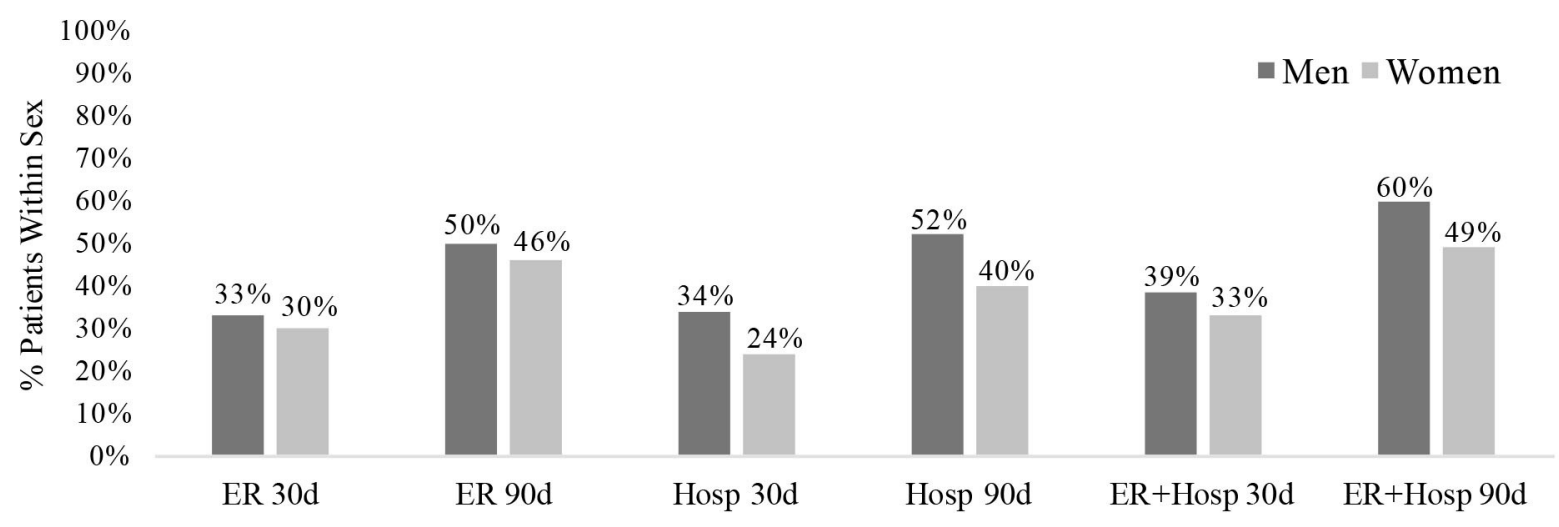

Figure 2 Emergency room (ER) visits and hospital (hosp) readmissions according to sex. d, days.

risk is greater in women when compared with the sexmatched population without diabetes. ${ }^{27-30}$ The absence of sex differences in the prevalence of diabetes-related macrovascular complications in this study is of interest, as these findings are consistent with prior publications demonstrating loss of the usual protective effect of female sex on risk of CVD observed in women without diabetes. 5282931

Women are reported as being less likely to use or receive preventive medical care, which can be crucial in identifying and treating both microvascular and macrovascular complications. ${ }^{53233}$ In one report, women diagnosed with diabetes in young adulthood were less likely to have access to annual eye and foot examinations. ${ }^{32}$ These disparities are more pronounced among women from lower socioeconomic backgrounds, where delays in diagnosis and treatment can increase disease-specific morbidity and mortality. ${ }^{6} 2932$

Patients with diabetes often experience hypoglycemia or hyperglycemia during periods of hospitalization, both of which are reported as being associated with risk of readmission. ${ }^{9} 3435$ With the exception of more hypoglycemic events in men, glycemic measures were otherwise similar in the 48 hours preceding hospital discharge in this study. Hypoglycemia is a common complication of inpatient insulin therapy and can result in increased morbidity and mortality that extend beyond the hospitalization when these events occur. ${ }^{36} 37$ The reasons for the more frequent hypoglycemia in men versus women were not investigated; however, over $90 \%$ of men and women in this report received insulin therapy, as recommended by current guidelines for inpatient glycemic management. ${ }^{38} 39$ Among the small percentage of patients receiving non-insulin therapy during hospitalization, none of the men and only one woman experiencing hypoglycemia received an insulin secretagogue, another risk factor for inpatient hypoglycemia. ${ }^{40}$ The findings of sex differences in hypoglycemic events are consistent with an earlier prospective cohort study of 250 patients which found that male sex was an independent predictor of asymptomatic hypoglycemia in hospitalized patients with diabetes. ${ }^{41}$ The reasons for this sex difference in hypoglycemic events are not known.

The frequency of ER visits and hospital readmissions at 30 and 90 days following the index hospitalization was similar among men and women in the current study. Prior studies that retrospectively examined risk factors for hospital readmission using large databases have variably demonstrated similar, less, or more frequent readmissions in women than in men. ${ }^{12} 13194243$ This variability is likely due in part to the type of database or study population examined. In one study of 737 hospitalized adults examining sex alone as a risk for readmission, men experienced more 30-day postdischarge ER visits and readmissions than women. ${ }^{42}$ However, the risk factors for these repeat visits differed between men and women. For men, social factors and depression were major predictors, while hospitalization in the preceding 6 months was the only identified factor for readmission among women. When examining the combination of sex and diabetes, there are less available data. In one study examining sex differences in healthcare expenditures, costs associated with ER visits and inpatient stays were equivalent between men and women. ${ }^{4}$

Changes in diabetes-related medications between time of admission and discharge are identified as a contributor to risk of hospital readmission in some but not all studies. ${ }^{44-46}$ In one study, women were more likely to have intensification of their diabetes regimen at the time of discharge. ${ }^{47}$ Another retrospective study of hospitalized patients with diabetes not on insulin prior to hospitalization showed no association with sex and medication 
intensification at time of hospital discharge. ${ }^{44}$ In the current study, there were no sex differences in changes in diabetes medications between admission and discharge, with the most common medication change being an adjustment in dose or type of insulin.

There are several limitations to this observational study. One is that patients in this study were recruited from a single academic university hospital, limiting the ability to apply these findings to other hospitalized, non-critically ill patient populations with diabetes across the USA. Another is the small sample size when compared with studies conducted using large patient databases. ${ }^{12} 181943$ This may have not allowed sufficient power to detect differences in outcomes that may in fact be present. An additional limitation is that information regarding social support at home that may have contributed to the higher percentage of women discharged to a skilled nursing facility was not obtained as part of this study. Finally, the population represented in this study was predominantly white. Although there were no race differences in readmission rates or ER visits, the percentage of non-white participants was small, which may have interfered with the ability to identify this as a potential contributor.

\section{CONCLUSION}

This study provides descriptive information regarding sex-based clinical and demographic characteristics among patients hospitalized with a secondary diagnosis of diabetes. Findings that were consistently observed between men and women included the presence of preadmission poor glycemic measures as defined by mean HbAlc values $>8 \%$, as well as poor glycemic outcomes during hospitalization with mean BG levels $>180 \mathrm{mg} / \mathrm{dL}$ associated with a high level of glycemic variability. The frequency of ER visits and hospital readmissions at 30 and 90 days was similar between men and women but exceeds what is reported in patient populations without diabetes. ${ }^{132148} 49$ In summary, the risk of hospital readmission was high in both men and women in this study. The factors contributing to hospital readmissions may differ between the sexes. Further investigations into potentially remediable factors contributing to readmission risk are recommended.

\section{Author affiliations}

'Department of Medicine, UPMC, Pittsburgh, Pennsylvania, USA

${ }^{2}$ School of Pharmacy, University of Pittsburgh, Pittsburgh, Pennsylvania, USA

${ }^{3}$ Division of Endocrinology and Metabolism, University of Pittsburgh, Pittsburgh, Pennsylvania, USA

${ }^{4}$ Department of Medicine/Endocrinology, Temple University School of Medicine, Philadelphia, Pennsylvania, USA

${ }^{5}$ Clinical and Translational Science Institute, University of Pittsburgh, Pittsburgh, Pennsylvania, USA

Contributors NP was involved in the recruitment and follow-up of study participants, data collection and analysis, and abstract and manuscript preparation. NP was responsible for the draft of this manuscript. JS designed the study and data collection tools and study database, submitted the protocol to the institutional review board for approval, and worked with other members of the study team to engage them in subject recruitment and study methods. JS submitted abstracts to the American Diabetes Association and the Endocrine Society, where early findings of this study were presented. She participated in the preparation of this manuscript. DP was involved in the recruitment and follow-up of study participants, data collection and analysis, and abstract and manuscript preparation. EKF, DH, and $\mathrm{KD}$ were involved in the recruitment and follow-up of study participants and data collection, and reviewed and submitted comments on this manuscript. AD and LS were involved in study design and development of data collection tools and development of the study database, and reviewed and submitted comments on this manuscript. DJR provided consultation regarding the study design and use of the DERRI calculator that was used in the assessment of patient participants. He reviewed and submitted comments on this manuscript. LW met with investigators (JS, DP, MTK) to discuss statistical analyses and development of data collection tools over the course of this study and performed all statistical analyses. She reviewed and provided comments on the manuscript. MTK was the senior author and guarantor responsible for the overall content of this manuscript. MTK accepts full responsibility for the work and conduct of this study, had access to all study data, and controlled the decision to publish.

Funding This work was supported in part by the National Institutes of Health through grant number UL1-TR-001857.

Competing interests DJR receives research funding from AstraZeneca. The other authors have no multiplicity of interest to disclose.

\section{Patient consent for publication Not required.}

Ethics approval This study involves human participants and was approved by the University of Pittsburgh Institutional Review Board (reference number: PR017050222). Participants gave informed consent to participate in the study before taking part.

Provenance and peer review Not commissioned; externally peer reviewed.

Data availability statement Data are available upon reasonable request. All data relevant to the study are included in the article.

Open access This is an open access article distributed in accordance with the Creative Commons Attribution Non Commercial (CC BY-NC 4.0) license, which permits others to distribute, remix, adapt, build upon this work noncommercially, and license their derivative works on different terms, provided the original work is properly cited, appropriate credit is given, any changes made indicated, and the use is non-commercial. See: http://creativecommons.org/ licenses/by-nc/4.0/.

ORCID iDs

Daniel J Rubin http://orcid.org/0000-0002-6871-6246

Mary T Korytkowski http://orcid.org/0000-0001-7131-8903

\section{REFERENCES}

1 Center for Disease Control. National diabetes statistics report 2020: estimates of diabetes and its burden in the United States 2020.

2 American Diabetes Association. Economic costs of diabetes in the U.S. in 2017. Diabetes Care 2018;41:917-28.

3 Leung M-YM, Pollack LM, Colditz GA, et al. Life years lost and lifetime health care expenditures associated with diabetes in the U.S., National health interview survey, 1997-2000. Diabetes Care 2015;38:460-8.

4 Williams JS, Bishu K, Dismuke CE, et al. Sex differences in healthcare expenditures among adults with diabetes: evidence from the medical expenditure panel survey, 2002-2011. BMC Health Serv Res 2017;17:259.

5 Kautzky-Willer A, Harreiter J, Pacini G. Sex and gender differences in risk, pathophysiology and complications of type 2 diabetes mellitus. Endocr Rev 2016;37:278-316.

6 Marshall CJ, Rodriguez HP, Dyer W, et al. Racial and ethnic disparities in diabetes care quality among women of reproductive age in an integrated delivery system. Women's Health Issues 2020;30:191-9.

7 Bo S, Ciccone G, Grassi G, et al. Patients with type 2 diabetes had higher rates of hospitalization than the general population. J Clin Epidemiol 2004;57:1196-201.

8 De Berardis G, D'Ettorre A, Graziano G, et al. The burden of hospitalization related to diabetes mellitus: a population-based study. Nutr Metab Cardiovasc Dis 2012;22:605-12.

9 Cook CB, Kongable GL, Potter DJ, et al. Inpatient glucose control: a glycemic survey of 126 U.S. hospitals. J Hosp Med 2009;4:E7-14. 
10 Rubin DJ, Recco D, Turchin A, et al. External validation of the diabetes early re-admission risk indicator (DERRI). Endocr Pract 2018;24:527-41.

11 Healy SJ, Black D, Harris C, et al. Inpatient diabetes education is associated with less frequent hospital readmission among patients with poor glycemic control. Diabetes Care 2013;36:2960-7.

12 Raval AD, Zhou S, Wei W, et al. 30-day readmission among elderly medicare beneficiaries with type 2 diabetes. Popul Health Manag 2015;18:256-64.

13 Rubin DJ. Hospital readmission of patients with diabetes. Curr Diab Rep 2015;15:17.

14 Cohn BA, Cirillo PM, Wingard DL, et al. Gender differences in hospitalizations for IDDM among adolescents in California, 1991. Implications for prevention. Diabetes Care 1997;20:1677-82.

15 Karunakaran A, Zhao H, Rubin DJ. Predischarge and postdischarge risk factors for hospital readmission among patients with diabetes. Med Care 2018;56:634-42.

16 Zuckerman RB, Sheingold SH, Epstein AM. The hospital readmissions reduction program. N Engl J Med 2016;375:494.

17 Zuckerman RB, Joynt Maddox KE, Sheingold SH, et al. Effect of a hospital-wide measure on the readmissions reduction program. $N$ Engl J Med 2017;377:1551-8.

18 Lee JM, Davis MM, Gebremariam A, et al. Age and sex differences in hospitalizations associated with diabetes. J Womens Health 2010;19:2033-42.

19 Gupta N, Crouse DL, Balram A. Individual and community-level income and the risk of diabetes rehospitalization among women and men: a Canadian population-based cohort study. BMC Public Health 2020;20:60.

20 Kwok CS, Potts J, Gulati M, et al. Effect of gender on unplanned readmissions after percutaneous coronary intervention (from the nationwide readmissions database). Am J Cardiol 2018;121:810-7.

21 Flink L, Mochari-Greenberger H, Mosca L. Gender differences in clinical outcomes among diabetic patients hospitalized for cardiovascular disease. Am Heart J 2013;165:972-8.

22 Lam L, Ahn HJ, Okajima K, et al. Gender differences in the rate of 30-day readmissions after percutaneous coronary intervention for acute coronary syndrome. Womens Health Issues 2019;29:17-22.

23 Pinkhasova D, Swami JB, Patel N, et al. Patient understanding of discharge instructions for home diabetes self-management and risk for hospital readmission and emergency department visits. Endocr Pract 2021:27:561-6.

24 Rubin DJ, Handorf EA, Golden SH, et al. Development and validation of a novel tool to predict hospital readmission risk among patients with diabetes. Endocr Pract 2016;22:1204-15.

25 Pollack $\mathrm{AH}$, Backonja U, Miller AD, et al. Closing the gap: supporting patients' transition to self-management after hospitalization. Proc SIGCHI Conf Hum Factor Comput Syst 2016;2016:5324-36

26 Rubin DJ, Donnell-Jackson K, Jhingan R, et al. Early readmission among patients with diabetes: a qualitative assessment of contributing factors. J Diabetes Complications 2014;28:869-73.

27 Arnetz L, Ekberg NR, Alvarsson M. Sex differences in type 2 diabetes: focus on disease course and outcomes. Diabetes Metab Syndr Obes 2014;7:409-20.

28 Booth GL, Kapral MK, Fung K, et al. Relation between age and cardiovascular disease in men and women with diabetes compared with non-diabetic people: a population-based retrospective cohort study. Lancet 2006;368:29-36.

29 Recarti C, Sep SJS, Stehouwer CDA, et al. Excess cardiovascular risk in diabetic women: a case for intensive treatment. Curr Hypertens Rep 2015;17:554.

30 Huxley RR, Peters SAE, Mishra GD, et al. Risk of all-cause mortality and vascular events in women versus men with type 1 diabetes: a systematic review and meta-analysis. Lancet Diabetes Endocrinol 2015;3:198-206.
31 Mattioli AV, Sciomer S, Moscucci F, et al. Cardiovascular prevention in women: a narrative review from the Italian Society of Cardiology working groups on 'Cardiovascular Prevention, Hypertension and peripheral circulation' and on 'Women Disease'. J Cardiovasc Med 2019;20:575-83.

32 Owens MD, Beckles GLA, Ho KK-Y, et al. Women with diagnosed diabetes across the life stages: underuse of recommended preventive care services. J Womens Health 2008;17:1415-23.

33 Gouni-Berthold I, Berthold HK, Mantzoros CS, et al. Sex disparities in the treatment and control of cardiovascular risk factors in type 2 diabetes. Diabetes Care 2008;31:1389-91.

34 Spanakis EK, Singh LG, Siddiqui T, et al. Association of glucose variability at the last day of hospitalization with 30-day readmission in adults with diabetes. BMJ Open Diabetes Res Care 2020;8:e000990.

35 Spanakis EK, Umpierrez GE, Siddiqui T, et al. Association of glucose concentrations at hospital discharge with readmissions and mortality: a nationwide cohort study. J Clin Endocrinol Metab 2019;104:3679-91.

36 Turchin A, Matheny ME, Shubina M, et al. Hypoglycemia and clinical outcomes in patients with diabetes hospitalized in the general ward. Diabetes Care 2009;32:1153-7.

37 Garg R, Hurwitz S, Turchin A, et al. Hypoglycemia, with or without insulin therapy, is associated with increased mortality among hospitalized patients. Diabetes Care 2013;36:1107-10.

38 Umpierrez GE, Hellman R, Korytkowski MT, et al. Management of hyperglycemia in hospitalized patients in non-critical care setting: an endocrine Society clinical practice guideline. J Clin Endocrinol Metab 2012;97:16-38.

39 American Diabetes Association. Diabetes care in the hospital standards of medical care in diabetes 2020. Diabetes Care 2020;43:S193-202.

40 Deusenberry CM, Coley KC, Korytkowski MT, et al. Hypoglycemia in hospitalized patients treated with sulfonylureas. Pharmacotherapy 2012;32:613-7.

41 Cardona S, Gomez PC, Vellanki P, et al. Clinical characteristics and outcomes of symptomatic and asymptomatic hypoglycemia in hospitalized patients with diabetes. BMJ Open Diabetes Res Care 2018;6:e000607.

42 Woz S, Mitchell S, Hesko C, et al. Gender as risk factor for 30 days post-discharge hospital utilisation: a secondary data analysis. BMJ Open 2012;2:e000428.

$43 \mathrm{Kim} \mathrm{H}$, Ross JS, Melkus GD, et al. Scheduled and unscheduled hospital readmissions among patients with diabetes. Am J Manag Care 2010:16:760-7.

44 Abusamaan MS, Fesseha Voss B, Kim HN, et al. Patterns and predictors of antihyperglycemic intensification at hospital discharge for type 2 diabetic patients not on home insulin. J Clin Trans/ Endocrinol 2020;20:100220.

45 Wei NJ, Wexler DJ, Nathan DM, et al. Intensification of diabetes medication and risk for 30-day readmission. Diabet Med 2013;30:e56-62

46 Lee $\mathrm{PH}$, Franks AS, Barlow PB, et al. Hospital readmission and emergency department use based on prescribing patterns in patients with severely uncontrolled type 2 diabetes mellitus. Diabetes Technol Ther 2014;16:150-5.

47 Buchholz C, Kahle-Stephan M, Meier JJ, et al. Clinical Predictors of the Need for Further Treatment Escalation in Patients with Type 2 Diabetes on Basal Insulin Therapy - A Retrospective Observational Study. Exp Clin Endocrinol Diabetes 2019;127:663-71.

48 Sonmez H, Kambo V, Avtanski D, et al. The readmission rates in patients with versus those without diabetes mellitus at an urban teaching hospital. J Diabetes Complications 2017;31:1681-5.

49 Ostling S, Wyckoff J, Ciarkowski SL, et al. The relationship between diabetes mellitus and 30-day readmission rates. Clin Diabetes Endocrinol 2017;3:3. 